Davis, G. H. G. \& Baird-Parker, A. C. (1959). J. gen. Microbiol. 21, 612-621

\title{
The Classification of Certain Filamentous Bacteria with Respect to their Ghemical Composition
}

\author{
By G. H. G. DAVIS ANd A. C. BAIRD-PARKER \\ Bacteriology Department, University of Birmingham
}

SUMMARY: Upon the basis of cell-wall composition the oral bacteria Leptotrichia dentium and $L$. buccalis appear to form a natural generic group related to Nocardia and possibly Lactobacillus. An aerobic oral actinomycete of the type commonly called Nocardia has been shown to resemble closely the anaerobic pathogenic Actinomyces which parasitizes man. The cell-wall composition of Streptomyces, Nocardia, Lactobacillus and Fusobacterium strains is also reported.

The purpose of this study is to determine the relationship between the filamentous bacteria of the oral flora and between these and the comparable forms from other sources.

The oral parasite, Leptotrichia dentium (Baird-Parker \& Davis, 1958; Davis \& Baird-Parker, 1959) possesses characters that suggest possible relationship with both Nocardia and Streptomyces. Nevertheless, it does not resemble either of these genera so closely as to make classification with one of them unequivocal upon morphological grounds alone. At the same time, the diagnostic characters of Streptomyces and Nocardia overlap to some extent; some species of the latter, e.g. $N$. asteroides, produce aerial mycelium and spores of distinctly Streptomyces-like appearance (Gordon \& Mihm, 1958) and the vegetative mycelium of Streptomyces commonly fragments to yield Nocardia-like elements (Bisset, 1957; Bradley \& Anderson, 1958).

It has, on the other hand, been suggested that Leptotrichia buccalis is closely related to Lactobacillus upon metabolic grounds (Hamilton \& Zahler, 1957).

Although Leptotrichia dentium more closely resembles the Actinomycetales in its morphology, it is physiologically similar to $L$. buccalis in many ways and partly for this reason, and partly for convenience, the two organisms currently constitute the ill-defined genus Leptotrichia.

Leptotrichia buccalis has also been frequently confused with Fusobacterium so that certain specific names in this genus [e.g. F. dentium (Hine \& Berry, 1937); F. plauti-vincenti (Jackins \& Barker, 1951)] are synonyms for L. buccalis.

It is apparent that the relationships of all these genera and species require to be re-examined.

A further problem is the occurrence in the mouth of aerobic Gram-positive filamentous bacteria usually classified as Nocardia spp. (Morris, 1954). Although some of these have been identified with previously described species, e.g. Nocardia corallina, N. rangoonensis, N. mesenterica, by Mandel, Levy \& Wasserman (1957) their taxonomy has not been developed to any great extent. Such organisms have been confused with the microaerophilic Actinomyces israelii and it is probable that the $A$. naeslundii of Thompson \& Lovestedt (1951) and 
Garrod (1952) represents one of the commonest of these oral organisms. The group $3 b$ of Onisi \& Nuckolls (1958) also appears to consist of such organisms.

We have attempted to resolve some of these problems by supplementing cultural, morphological and metabolic studies with chromatographic analyses of cell walls according to the technique of Cummins \& Harris $(1956,1958)$.

\section{MA'TERIALS AND METHODS}

See Table 1 for strains used and their origins. The soil strains of Nocardia were supplied by Dr R. B. Cain of this department.

The isolation and maintenance of Leptotrichia dentium and $L$. buccalis has been described elsewhere (Davis \& Baird-Parker, 1959) and so also has the isolation and classification of Lactobacillus spp. (Davis, 1955), and the isolation of Fusobacterium spp. (Baird-Parker, 1957).

Table 1. Strains examined

\begin{tabular}{cll} 
Strain no. & \multicolumn{1}{c}{$\begin{array}{c}\text { Description } \\
\text { SG }\end{array}$} & $\begin{array}{c}\text { Source } \\
\text { Old laboratory } \\
\text { culture }\end{array}$ \\
S25 & Streptomyces griseus & Soil \\
S26 & Streptomyces sp. & Soil \\
600 & S. hortonensis & NCTC \\
4523 & Actinomyces buccalis & NCTC \\
8595 & Nocardia asteroides & NCTC \\
C1 & Nocardia sp. & Soil \\
C2 & Nocardia sp. & Soil \\
2A1 & Leptotrichia dentium & Human saliva \\
1C1 & L. dentium & Human saliva \\
V1 & L. dentium & Human saliva \\
LD & L. dentium & Human saliva \\
LB1 & Leptotrichia buccalis & Human saliva \\
LB2 & L. buccalis & Human saliva \\
LB3 & L. buccalis & Human saliva \\
G5A & Aerobic actinomycete & Human saliva \\
T3 & Aerobic actinomycete & Human saliva \\
4A & Lactobacillus fermenti & Human saliva \\
6G & L. buchneri & Human saliva \\
3D & L. plantarum & Human saliva \\
2A & L. casei & Human saliva \\
8C & L. salivarius & Human saliva \\
1A & L. acidophilus & Human saliva \\
F18 & Fusobacterium sp. & Human saliva \\
FP & Fusobacterium sp. & Human saliva
\end{tabular}

Oral aerobic actinomycetes were isolated upon nutrient agar supplemented with $0.3 \%(w / v)$ yeast extract and $0 \cdot 2 \%(w / v)$ soluble starch. This medium was also used for the maintenance of Streptomyces, Nocardia, and the NCTC strains.

\section{Chromatographic analysis}

Cell growth. All strains were grown in.liquid media in bulk cultures. The aerobic organisms, i.e. Nocardia, Streptomyces, Leptotrichia dentium, oral aerobic actinomycetes, and NCTC strains were inoculated into Carrel type flasks containing $200 \mathrm{ml}$. of nutrient broth plus $1 \%(\mathrm{w} / \mathrm{v})$ glucose and $0.2 \%$ 
$(\mathrm{w} / \mathrm{v})$ soluble starch, $\mathrm{pH} 7 \cdot 4$, in shallow layers. Soil bacteria were incubated at $28^{\circ}$, the rest at $37^{\circ}$, and the flasks shaken daily to distribute growth. Cells were harvested when good growth was evident, usually 3-5 days.

Lactobacillus strains were cultured in screw-capped bottles containing the following medium: vitamin-free casein hydrolysate $20 \mathrm{~g}$., yeast-extract $5 \mathrm{~g}$., sodium acetate 15 g., glucose 20 g., salts A 5 ml., salts $B 5 \mathrm{ml}$., Tween $801 \mathrm{ml}$., distilled water $1000 \mathrm{ml}$., pH 7·0. (For salts A and B see Hayward, 1957.)

Inoculated bottles of medium were loosely closed, especially in the case of heterofermentative strains, to allow generated gas to escape.

Anaerobic organisms (Leptotrichia buccalis and Fusobacterium) were grown in tightly closed screw-capped bottles completely filled with Baird-Parker's (1957) medium, omitting the antibiotics and dye.

Cells were harvested by centrifuging, and washed three times in distilled water. (In some cases, e.g. Nocardia and Streptomyces, the alkaline ethanol treatment of Cummins \& Harris (1958) was applied.) The cell mass was divided into two parts with normally the harvest of $200 \mathrm{ml}$. of medium in each.

Sugar extracts. One sample of cells was suspended in c. $5 . \mathrm{ml}$. of $2 \mathrm{~N}-\mathrm{H}_{2} \mathrm{SO}_{4}$ in a tightly closed $20 \mathrm{ml}$. screw-capped McCartney bottle, and heated for $4 \mathrm{hr}$. in a steamer. This whole cell hydrolysate was neutralized to $\mathrm{pH} 4.8 \mathrm{using}$ freshly prepared saturated barium hydroxide solution and methyl red as indicator. Precipitated sulphate and cells were removed by centrifuging and the clear supernatant evaporated to dryness in vacuum over calcium chloride. The extract was re-suspended in $c .0 \cdot 2-0.5 \mathrm{ml} .10 \%$ iso-propyl alcohol solution.

Amino acid extracts. The second sample of cells was made into a thick slurry with water and the cells broken by exposing them to high-frequency vibrations using a 'Mullard' $60 \mathrm{~W}$. ultrasonic drill fed by an amplifier, supplying $180 \mathrm{~W}$. at $20,000 \mathrm{kc} . / \mathrm{s}$.

The rate of cell breakage by this method varies greatly with different types of organism. Gram-negative organisms (Fusobacterium, Escherichia coli) break readily (1-2 min. exposure); Gram-positive filamentous bacteria (Streptomyces, Corynebacterium, etc.) require 20-30 min.; small Grampositive bacilli (certain lactobacilli) and coccal forms are difficult to rupture, requiring $1 \mathrm{hr}$. or more. Broken cells were centrifuged, resuspended in $\mathbf{0 . 5} \%$ trypsin solution, and solid sodium bicarbonate added to produce $c$. pH 8*6. trypsin digestion was carried out at $37^{\circ}$ for $12-18 \mathrm{hr}$; the cell walls were centrifuged, washed three times in distilled water, and resuspended in $c .5 \mathrm{ml}$. $6 \mathrm{~N}-\mathrm{HCl}$. Hydrolysis was carried out in tightly closed screw-capped McCartney bottles by autoclaving at 25-30 lb./sq.in. pressure for $4 \mathrm{hr}$. The hydrolysate was filtered through sintered glass (porosity no. 4), evaporated to dryness on a steam bath, re-dissolved in 1-2 ml. 10\% iso-propyl alcohol, one spot of concentrated ammonia added and the extract refiltered, evaporated dry and re-dissolved in .c. $0.3 \mathrm{ml} .10 \%$ iso-propyl alcohol.

Chromatography. Amino acid and sugar extracts were analysed by paper chromatography using the descending, one-dimensional method, and Whatman no. 1 paper. 
Each extract was run in two solvents.

Sugars : (a) Iso-propyl alcohol (160) + water (40).

(b) Phenol (80) + water (20).

Amino acids : (a) Iso-propyl alcohol (70) + acetic acid (10) + water (20).

(b) Phenol (80) + water $(20)+8$ hydroxyquinoline $(0.008 \mathrm{~g} . /$ $100 \mathrm{ml}$.) in an atmosphere of ammonia.

Owing to the varying concentrations of different extracts, it was found advantageous to run each extract at three or four concentrations upon the chromatogram. This was achieved by using a platinum loop to load the chromatogram, applying, for example, 2, 6 and 10 spots. while gently heating with a hair-dryer to control the spot size.

Sugar chromatograms were air-dried, dipped in aniline hydrogen phthalate and heated at $105^{\circ} \mathrm{C}$. for $5 \mathrm{~min}$.

Amino acid chromatograms were sprayed with $0.25 \%(w / v)$ ninhydrin in acetone and heated at $105^{\circ} \mathrm{C}$. for $5 \mathrm{~min}$.

The isomers of diaminopimelic acid were differentiated, as far as this is possible, using Hoare \& Work's (1957) method.

\section{Biochemical and cultural characters}

It is commonly stated that biochemical and cultural characters are of little value in differentiating Gram-positive filamentous bacteria into definite groups. In view of the small numbers of strains here described we would not dispute this statement, but simply record the results of certain tests which seem to us to be of possible value in the characterization of the aerobic types we have studied (Table 2). The differentiation of Leptotrichia buccalis from L. dentium has been described (Davis \& Baird-Parker, 1959) and the characteristics of Fusobacterium spp. will form the basis of a subsequent publication.

Casein digestion and Xanthine and Tyrosine dissolution tests were carried out as described by Gordon \& Mihm. (1956). Gelatin liquefaction was tested by the method of Frazier (1926). Routine methods were used for the remaining tests.

\section{RESULTS}

The results are set out in Tables 2-4.. In recording the cell-wall patterns we have adopted an arbitrary method whereby the major components are scored as positives and the minor components as traces. Using the relatively simple chromatographic methods here described it is considered safest to allow taxonomic significance only to major components, and as can be seen in Table 3 this renders the classification of organisms into groups at generic level quite easy. Seven such groups were differentiated and their salient cell-wall characteristics are compared in Table 4i. The analyses obtained for Streptomyces, Nocardia and Lactobacillus spp. agree in the main with those reported by Cummins \& Harris $(1956,1958)$. It will be noted that most of the bacteria yield ribose upon sugar analysis; this is to be expected in view of the presence of ribonucleic acid in bacteria; it is unlikely, however, that any other sugar is 


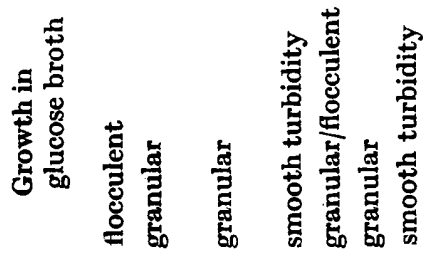

Growth temperature

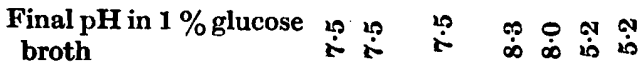

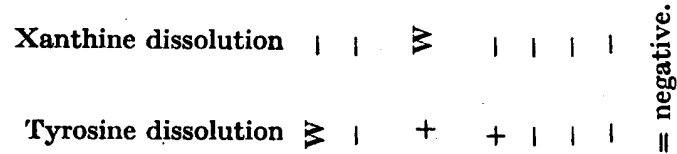
Hippurate hydrolysis $1,1 \geqslant 1+1$ Casein digestion $+\geq+1111$ Starch hydrolysis +++3$\}+\xi$ Gelatin liquefaction $+++1,1+3$ Nitrite reduction $1,1,1,+$ 悹 Nitrate reduction $1+1$ II Catalase production ++++++ No. of strains $\infty \rightarrow-\infty \rightarrow+\infty$ ง่

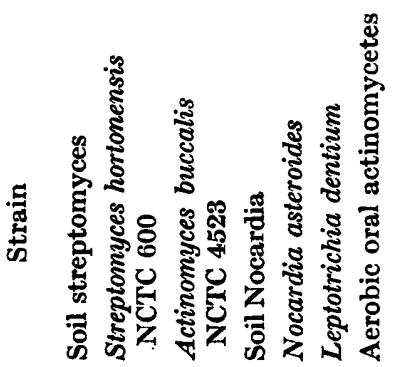




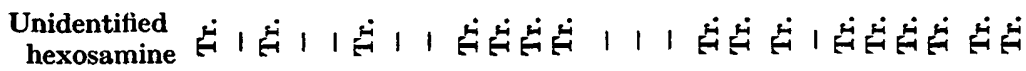

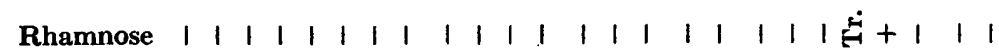
Galactose $|1| 1|1+++1| 1|1| 1|++1| 1$ |

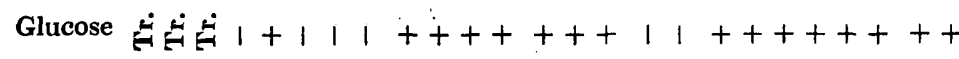
Ribose

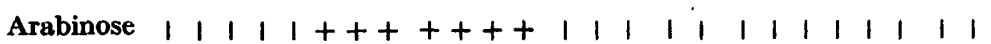

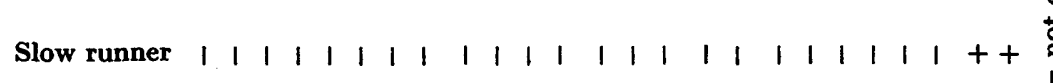

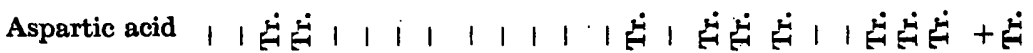

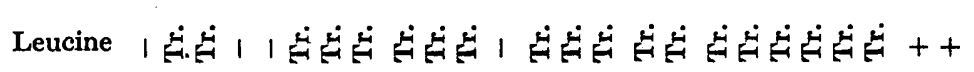

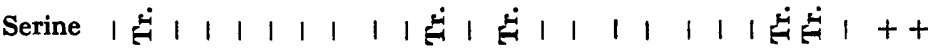

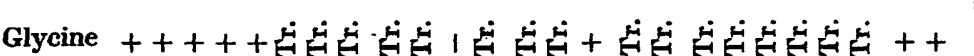

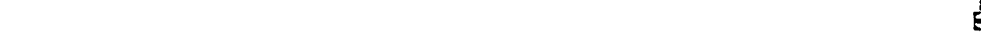
Alanine $++t+t+t+t+t+t+t+t+t+t+$ Glutamic acid $++++++++++t+++++++++++t$ Lysine 1 सُ DL-or DD-Diaminopimelic acid

$$
\begin{aligned}
& \begin{array}{l}
\text { pL-Diamino- } \\
\text { pimelic acid }
\end{array}++++\begin{array}{llllllllllllllllllll}
1 & 1 & 1 & 1 & 1 & 1 & 1 & 1 & 1 & 1 & 1 & 1 & 1 & 1 & 1 & 1 & 1 & 1 & 1 & 1
\end{array}
\end{aligned}
$$

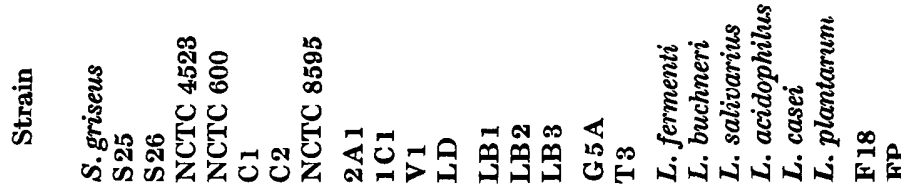

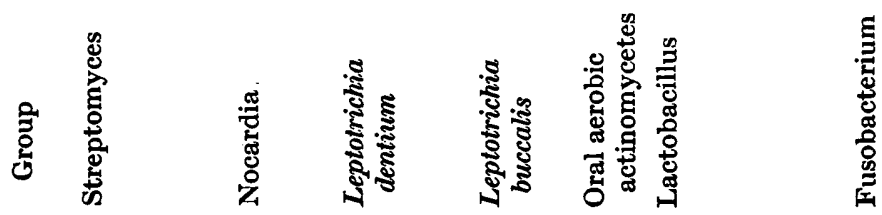




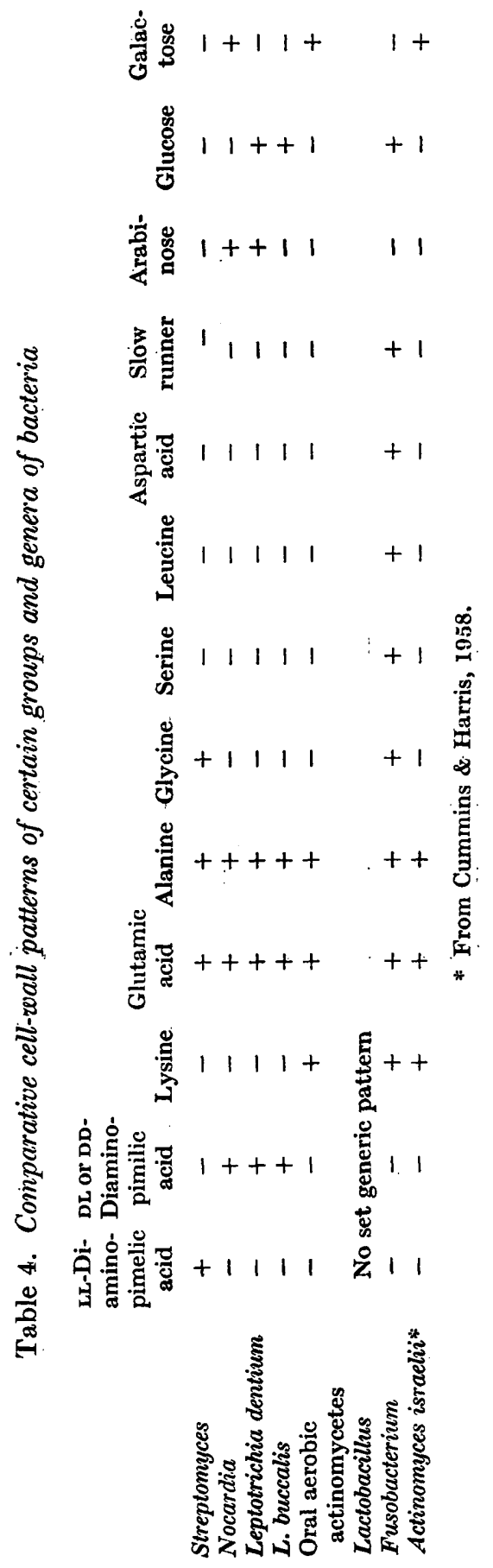


commonly present in large amounts in the cytoplasm or nucleus and the nonribose sugars detected in whole cell hydrolysates may be assumed to be cellwall components. We have compared sugar analyses of whole cells and cell walls in a few representative strains and found them to be identical.

Amino sugars, which appear to occur almost universally in bacterial cell walls, were not readily detected by the methods here described. They could not be picked out upon the amino acid chromatograms, but were often noticeable in the sugar runs. However, the latter method does not allow their clear differentiation in most cases and spots representing glucosamine, galactosamine or muramic acid are therefore recorded under a common heading as hexosamines (Table 3).

\section{DISCUSSION}

The classification of bacteria must depend upon information obtained by the use of various techniques. Chemical analysis of bacterial cellular components appears to be a useful method of confirming taxonomic groupings and in some cases clarifying relationships, which may be otherwise obscure, between certain bacteria.

In the present study we have tried to keep the technical work within the scope of the non-specialist and extract the maximum of useful information by: the simplest means, hence the use of whole cell hydrolysates for sugar analyses and one-dimensional chromatography. The questions posed in the introduction to this paper may be answered as follows:

Leptotrichia dentium resembles the genus Nocardia in cell-wall amino-acid pattern, but differs from it in sugar pattern. No relationship with the genus Streptomyces is indicated.

Leptotrichia dentium and $L$. buccalis exhibit the same amino acid patterns but differ by the absence of arabinose in the sugar component of $L$. buccalis. Whether these results indicate that the two organisms may be regarded without doubt as two species of a single genus depends upon the taxonomic significance placed upon the amino-acid and sugar patterns respectively. It has been suggested that the amino-acid patterns characterize genera and sugar patterns species, but too little evidence is yet available to prove this idea. In the Nocardia-Corynebacterium-Mycobacterium group of genera there appears to be little variation in either pattern between different species or even genera (Cummins \& Harris, 1958). Although lacking final proof it therefore seems reasonable to retain the genus Leptotrichia as distinct from, but closely related to, the genus Nocardia and to retain L. dentium and L. buccalis as its two species.

Among the lactobacilli, Lactobacillus plantarum and $\boldsymbol{L}$. casei show cell-wall patterns grossly similar to Leptotrichia buccalis in both amino acids and sugars. In contrast to such groups as Nocardia-Mycobacterium referred to above, there is considerable variation of pattern between species of the genus Lactobacillus and upon the basis of cell-wall pattern and physiology the inclusion of Leptotrichia buccalis as a species of the genus Lactobacillus would not appear anomalous. Morphologically, however, no Lactobacillus sp. resembles the distinctive Leptotrichia buccalis form, nor is it feasible to place $\boldsymbol{L}$. dentium 
with the lactobacilli on morphological or physiological grounds. The question thus resolves into the choice between placing $L$. buccalis in the genus Lactobacillus and Leptotrichia dentium in the genus Nocardia, with neither grouping being perfect, or retaining the genus Leptotrichia as suggested above. Fusobacterium spp. have a cell-wall pattern distinguished by its relative complexity and the presence of a distinctive slow running component of unknown composition. Amino acid complexity is characteristic of the cell walls of Gramnegative species. The slow running component runs slower than diaminopimelic acid in the iso-propyl alcohol solvent, and in Hoare \& Work's solvent it can be separated into two slow running spots.

The Nocardia-like aerobic actinomycetes isolated from the human mouth for this study are not classifiable as members of the genus Nocardia on the evidence of cell-wall patterns. They lack both diaminopimelic acid and arabinose, and upon the results so far available appear to have a cell-wall composition very like the true, microaerophilic Actinomyces of human origin (Cummins \& Harris, 1958). If this classification should prove correct the definition of the genus Actinomyces will require modification to include aerobic non-pathogenic organisms of this type.

It is interesting to note that the soil Nocardia strains are identical in cellwall composition with Nocardia asteroides, which is morphologically quite different from them in that it produces aerial chains of spores. The only Nocardia spp. investigated by Cummins \& Harris (1958) which was not of animal origin, was $N$. gardneri and this turned out to be a Streptomyces. Although Nocardia is predominantly a saprophytic genus, the atypical animal strains are commonly used as examples of the group; our results show that Nocardia spp. from saprophytic and parasitic sites, differing widely in morphological potential, nevertheless form a cohesive group in terms of cell-wall composition.

Upon biochemical as well as cell-wall characters the NCTC strain 4523 called Actinomyces buccalis should be re-classified with Streptomyces.

\section{REFERENCES}

Baird-Parker, A. C. (1957). Isolation of Leptotrichia buccalis and Fusobacterium species from oral material. Nature, Lond. 180, 1056.

Baird-Parker, A. C. \& Davis, G. H. G. (1958). The morphology of Leptotrichia species. J. gen. Microbiol. 19, 446.

BissET, K. A. (1957). Some observations upon the mode of sporulation and relationships of monosporous Actinomycetes. J. gen. Microbiol. 17, 562.

Bradley, S. G. \& Anderson, D. L. (1958). Comparative study on Nocardia and Streptomyces: Bact. Proc. p. 49.

Cummins, C. S. \& Harris, H. (1956). The chemical composition of the cell walls in some Gram-positive bacteria and its possible value as a taxonomic çaracter. J. gen. Microbiol. 14, 583.

Cummins, C. S. \& Harris, H. (1958). Studies on the cell-wall composition and taxonomy of Actinomycetales and related groups. J. gen. Microbiol. 18, 173.

Davis, G. H. G. (1955). The classification of Lactobacilli from the human mouth. J. gen. Microbiol. 13, 481. 
Davis, G. H. G. \& Baird-PARker, A. C. (1959). Leptotrichia buccalis. Brit. dent. J. 106, 70.

Frazier, W. C. (1926). A method for the detection of change in gelatin due to bacteria. J. infect. Dis. 39, 302.

Garrod, L. P. (1952). Actinomycosis of the lung: aetiology, diagnosis and chemotherapy. Tubercle, 33, 258.

Gordon, R. E. \& Mrhm, J. M. (1957). Comparative study of some strains received as Nocardiae. J. Bact. 73, 15.

Gordon, R. E. \& Mrнm, J. M. (1958). Sporulation by two strains of Nocardia asteroides. J. Bact. 75, 239.

Hamilton, R. D. \& Zahler, S. A.(1957). A study of Leptotrichia buccalis. J. Bact. 73, 386.

HAYward, A. C. (1957). Detection of gas production from glucose by heterofermentative lactic acid bacteria. J. gen. Microbiol. 16, 9.

Hine, M. K. \& Berry, G. P. (1937). Morphological and cultural studies of the genus Fusiformis. J. Bact. 34, 517.

Hoare, D. S. \& Work, E. (1957). The stereoisomers of $\alpha$ - $\epsilon$-diaminopimelic acid. 2. Their distribution in the bacterial order Actinomycetales and in certain Eubacteriales. Biochem. J. 65, 441 .

J ACKINS, H. C. \& Barker, H. A. (1951). Fermentation processes of the fusiform bacteria. J. Bact. 61, 101.

Mandel, I. D., Levy, B. M. \& Wasserman, B. H. (1957). Histochemistry of calculus formation. J. Periodont. 28, 132.

MorRIs, E. O. (1954). The bacteriology of the oral cavity. V. Corynebacterium and Gram-positive filamentous organisms. Brit. dent. J. 97, 29.

Onisi, M. \& Nuckolls, J. (1958). Descriptions of actinomycetes and other pleomorphic organisms recovered from pigmented carious lesions of the dentine of human teeth. Oral Surg. 11, 910.

Thompson, L. \& Lovestedt, S. A. (1951). An actinomyces-like organism obtained from the human mouth. Proc. Mayo Clin. 26, 169.

(Received 30 April 1959) 